\title{
OPTIMAL CROSS-SECTIONAL DESIGN FOR MINIMUM EMBODIED ENERGY
}

\author{
Dr Luisa María Gil Martín* \\ Campus Universitario de Fuentenueva, University of Granada, Granada, Spain \\ Dr Enrique Hernández Montes \\ Campus Universitario de Fuentenueva , University of Granada , Granada, Spain
}

In order to reduce the $\mathrm{CO}_{2}$ emission engineers and architects must optimize the use of materials, particularly steel, making an optimal use of it. It is possible to guarantee the strength of the structural element reducing the amount of steel locating it properly at the cross-section and introducing a higher control level at construction site

Key words: Sustainable construction, Embodied energy, Saving of steel

\section{INTRODUCTION}

Global warming due to greenhouse gases emissions is a worldwide problem. It is known that greenhouse gases are mainly sourced from the burning of fossil fuel being of all the gas emissions those $\mathrm{CO}_{2}$ is by far the most important. The problem relating to the global warming had become so important that 175 countries decided in 2005 in Kyoto (Protocol of Kyoto) decrease by $8 \%$ the greenhouse gases emissions during 2008 to 2010 compared to 1990 levels.

The steel is one of the most environmental careful products because of its high recycling rate and comparatively low quantities of energy required for its making. However, because the steel industry has a strong dependence on fossil fuels as energy source and limestone for the purification of iron oxides, the amount of emission of $\mathrm{CO}_{2}$ emitted during its fabrication process is very large. Motivated by social and economic reasons steel plants had introduced modern technology to save energy and treat the waste generated during the production process. Despite these actions, the environment problem associated with the greenhouse gases emissions remains the key issue in the international steel industry.

The steelmaker companies have the installations necessaries to produce steel sheets starting from raw materials (mainly iron ore and coal). Quite a few of these processes involve very high temperatures or tremendous forces. All these energy-intensive processes have a significant impact on the environment. In the last years, companies are looking for ways to reduce the environmental impact of its activities and to control its processes more efficiently. These actions have involved huge costs for firms. However, the sustainability for the steel industry concerns not only to the production of this material but also to the introduction to a rational consumption pattern. In this sense, an adequate awareness of engineers focused on a more rational use of steel can significantly reduce the consumed amount of this material, with the consequent environmental and economic benefits.

\section{ENVIRONMENTAL COST OF STEEL}

Carbon credits are one of the three mechanisms proposed in the Kyoto Protocol for reducing emissions that cause global warming or greenhouse gases (GHG). The GHG emission reductions are measured in terms of Certified Emission Reductions (CER). Each CER equals one tonne of $\mathrm{CO}_{2}$ that is allowed to emit into the atmosphere. This system tries to motivate to companies to controlling the regular emissions generated by their production processes. Since 2008, the system of the Community Emissions Trading Scheme (ETS), applies to the countries of the European Economic Area (Member States, Norway, Ice land and Liechtenstein). The ETS aims to help EU Member States meet their commitments to limit or reduce emissions of greenhouse gases cost-effectively, allowing to companies buy or sell emission allowances. A carbon credit entitles the holder to emit one tone of $\mathrm{CO}_{2}$. Imposing a 
cap on the total number of allowances is what creates scarcity in the market so companies that not emit or reduce the emission have benefits while had to pay if emissions are bigger than allowed.

Accepting that the average carbon dioxide emission is 2 Tons per tonne of steel, it is possible to estimate the environmental cost associated to the production of this material. In this paper the average value of $14 € /$ Ton of $\mathrm{CO}_{2}$ emissions is adopted and, in order to estimate the cost of the steel, has been accepted that the price of each ton of steel is $1 €$ and that the specific weight of steel is $78.5 \mathrm{kN} / \mathrm{m}^{3}$.

\section{STEEL IN STRUCTURES}

Until now, the main uses of steel have been in the transport, packaging and construction sectors. In the latter, i.e. civil engineering and architecture, the steel is usually used alone or in combination with concrete. In the second case, the steel is re- sponsible for resisting tensile stresses while the concrete is placed in the compressed area of the cross section, in which the steel is susceptible to instabilities. In this paper is shown that an optimal distribution of steel in the cross-section can save very important amount of steel.

\section{Reinforced concrete structure}

The design of longitudinal reinforcement in reinforced concrete structures is often made with the assistance of $\mathrm{N}-\mathrm{M}$ interaction diagrams, which generally are presented only for symmetric reinforcement. However, it is evident from RSD design approaches $[01,02]$ that in some cases it is feasible and economically advantageous to use asymmetric reinforcement distributions.

RSD methodology consists in the consideration of all the possible solutions, for a design problem, through the representation called RSD, as illustrated for a reinforced concrete section in Figure 1 [03].
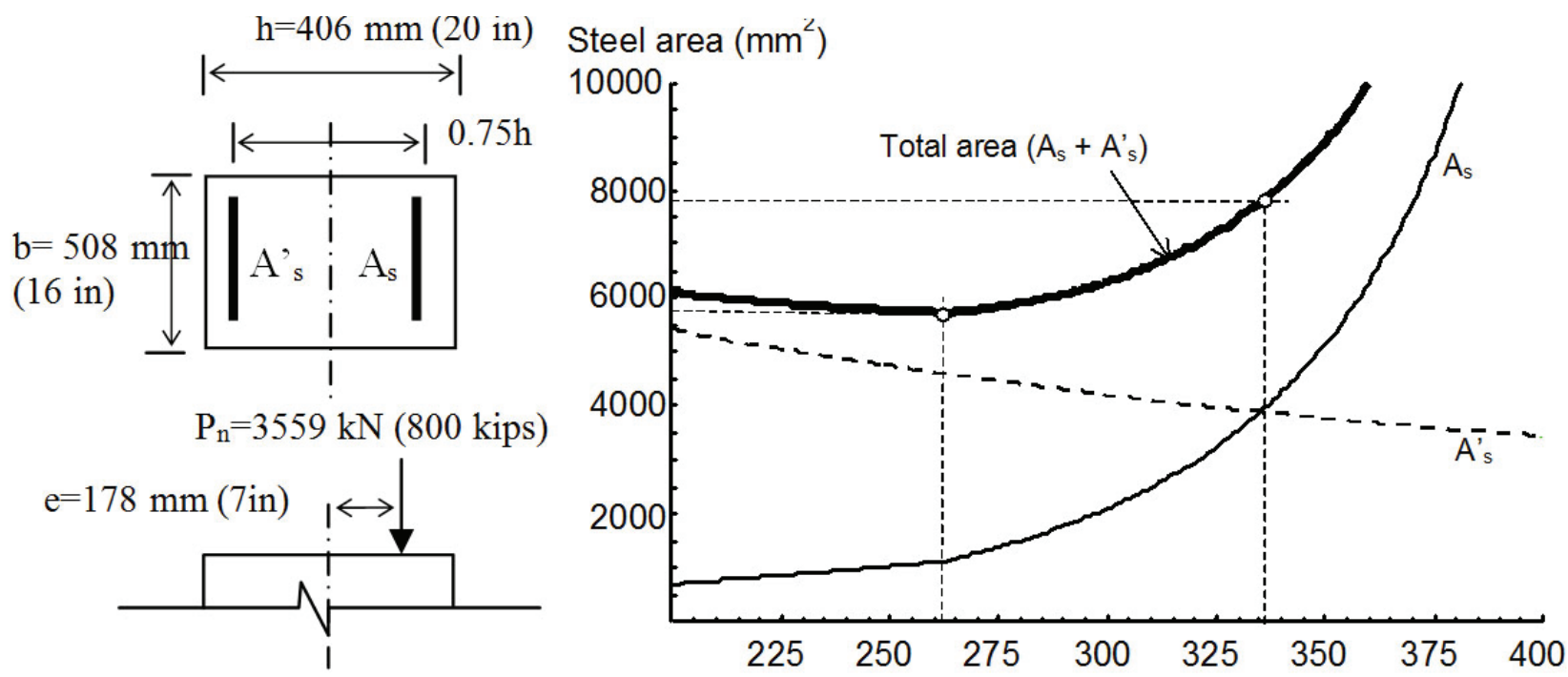

Figure 1: Example of RSD for uniaxial bending

Recent work by the authors has emphasized a unique solution strategy in which reinforcement solutions are obtained as a function of the neutral axis depth, allowing optimal reinforcement solutions to be characterized and used for design. The resulting reinforcement distributions generally are not symmetric, but conform to building code requirements and may result in significant savings of reinforcement, and thus advance the aims of sustainability in construction. In one instance, Reinforcement Sizing Diagrams are applied to the design of sections subjected to uniaxial bending in conjunction with axial load [03].
Although this non-symmetrical reinforcement in elements subjected to both bending moment and compression load represents a major advance in the state of the art of reinforced concrete, its applicability to piles of structures is very limited due to the random nature of the horizontal forces due to wind and earthquake. In order to account for the possible reversal of sign of the bending moments symmetrically reinforced piles have to be disposed. On the contrary, in situations in which such reversal of sign of the bending moment is not possible, a non-symmetrical reinforcement of the cross-section of concrete can save a sig- 
nificant quantity of steel. This situation happens in earth retention walls, in which the tensile zone will be always placed next to the soil because the unidirectional action of passive earth pressures.

In cities is very frequent the use of cut and cover excavation systems for projects such as subways, depressed rail and road bed. In these cases a temporary decking is included resting on the top of the retaining wall to permit traffic to use the space overhead while the construction process continue below (Figure 4). In such situations, the cast in place cantilever wall is very often constructed by circular piers of reinforced concrete because the pier foundations are less costly to construct than continuous wall founda- tions, simply due to the fact they use less material.

\section{Circular pier reinforced with steel cages}

Walls of piles (Figure 2.a), frequently used in underground construction, are routinely constructed using symmetric reinforcement (Figure 2.b). Design solutions for circular sections obtained with available computer programs and charts are built on the premise that the longitudinal reinforcement consists of a uniform bar diameter $(\phi)$ distributed evenly around the perimeter of the section, at a constant spacing. Nevertheless It has been shown that this reinforcement can be optimized [04, 05].

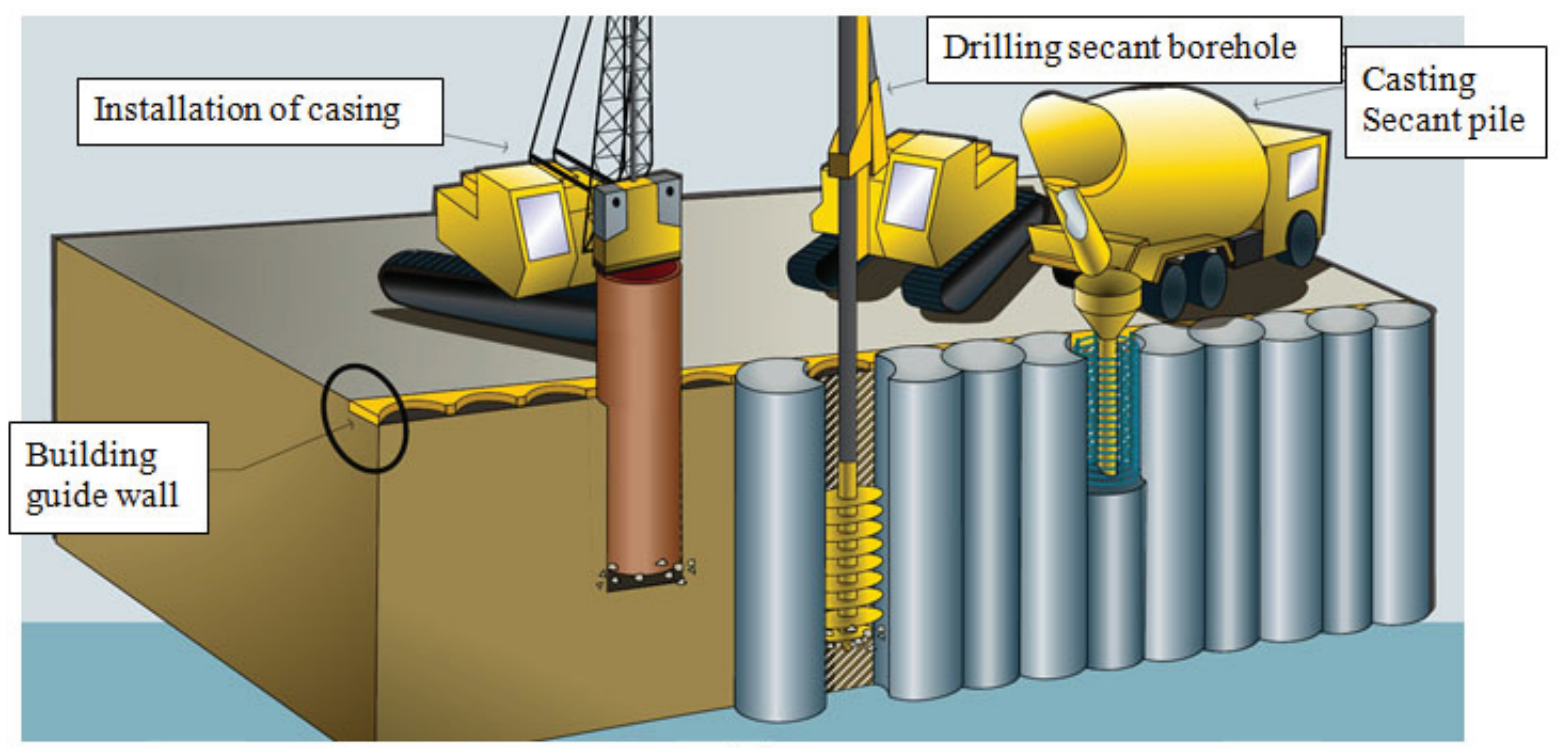

(a)

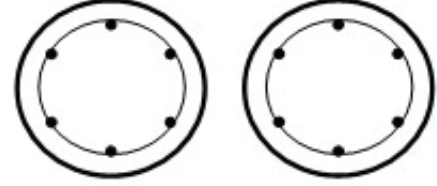

Contiguous piles

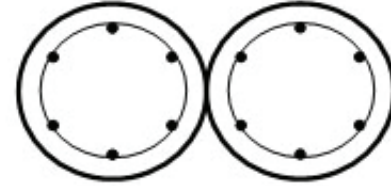

Tangent piles

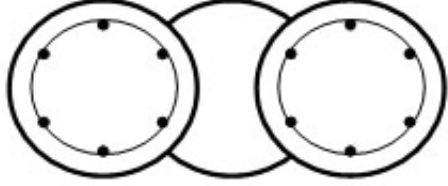

Secant piles

(b)

Figure 2: a. Secant wall construction (adapted from an archive of Land Transportation Authority, USA), b. Types of bored piles walls whit Traditional longitudinal reinforcement

In earth retaining structures, in light of the relatively insignificant axial compression sustained and because the unidirectional action of passive earth pressures results in a well defined monotonic direction of action for the design flexural moment at the critical cross-section - with no transverse components -, an alternative reinforcing arrangements such as those shown in Figure 3 may be more appropriate.
A pier with a diameter of $1 \mathrm{~m}$ will be considered in this paper. The conventional design utilized twenty $\phi 25$ bars for longitudinal reinforcement, with circular hoops of $\phi 8 @ 300$ mm. The design axial force is approximately zero. Steel reinforcement was B-500-S having a characteristic strength of $500 \mathrm{MPa}$. Concrete, C-25, had a nominal compressive strength of $25 \mathrm{MPa}$. The total area of initially projected longitudinal rein- 
forcement (twenty $\phi 25$ ) was $9817 \mathrm{~mm}^{2}$ or 1.25 $\%$ of the gross area. Initial and optimized reinforcement locations are shown in Figure 3.

As shows in Table 1, reinforcement savings of $44 \%$ can be obtained when two different bar diameters were used as shown in Figure 3(b), with

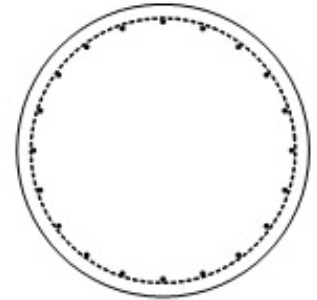

(a) the same flexural strength that the traditional designed pier -with symmetrically arranged longitudinal reinforcement (Figure 3(a)). This reduction in weight of steel implies a reduction in both the cost of transportation and the machinery for erection (cranes) of the reinforcement cages.

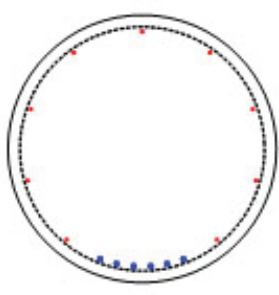

(b)

Figure 3: Piers of retaining wall a) Initial reinforcement b) Optimized reinforcement

In Figure 4 the interaction diagrams for both traditional and optimized piers in Table 1 have been represented. Figure 4 show that both piers have the same capacity in pure bending. So, Table 1 and Figure 4 show that the design bending moment can be carried adequately by cross sections containing alternative reinforcing arrangements such as this shown in Figure 3.b with an important saving in the use of steel reinforcement and without any loss of stiffness or strength properties. The primary advantage of those alternatives being the significant economy in reinforcing steel, they incur great savings in terms of embodied energy and cost as compared with the conventional symmetrical solution (Figure 3.a).

Table 1: Longitudinal reinforcement of piles. Initial and optimized solutions pure bending

\begin{tabular}{|c|c|c||c|}
\hline Solution & Bar composition & Area of steel $\left(\mathrm{mm}^{2}\right)$ & $\mathrm{M}_{\mathrm{u}}(\mathrm{kN} \cdot \mathrm{m})$ \\
\hline Initial -traditional- & $20 \phi 25$ & 9817.5 & 1712 \\
\hline $\begin{array}{c}\text { Optimization of the } \\
\text { reinforcement }\end{array}$ & $\begin{array}{c}6 \phi 32 @ 64 \mathrm{~mm} \\
+9 \phi 10 @ 270 \mathrm{~mm}\end{array}$ & 5532.3 & 1722 \\
\hline
\end{tabular}

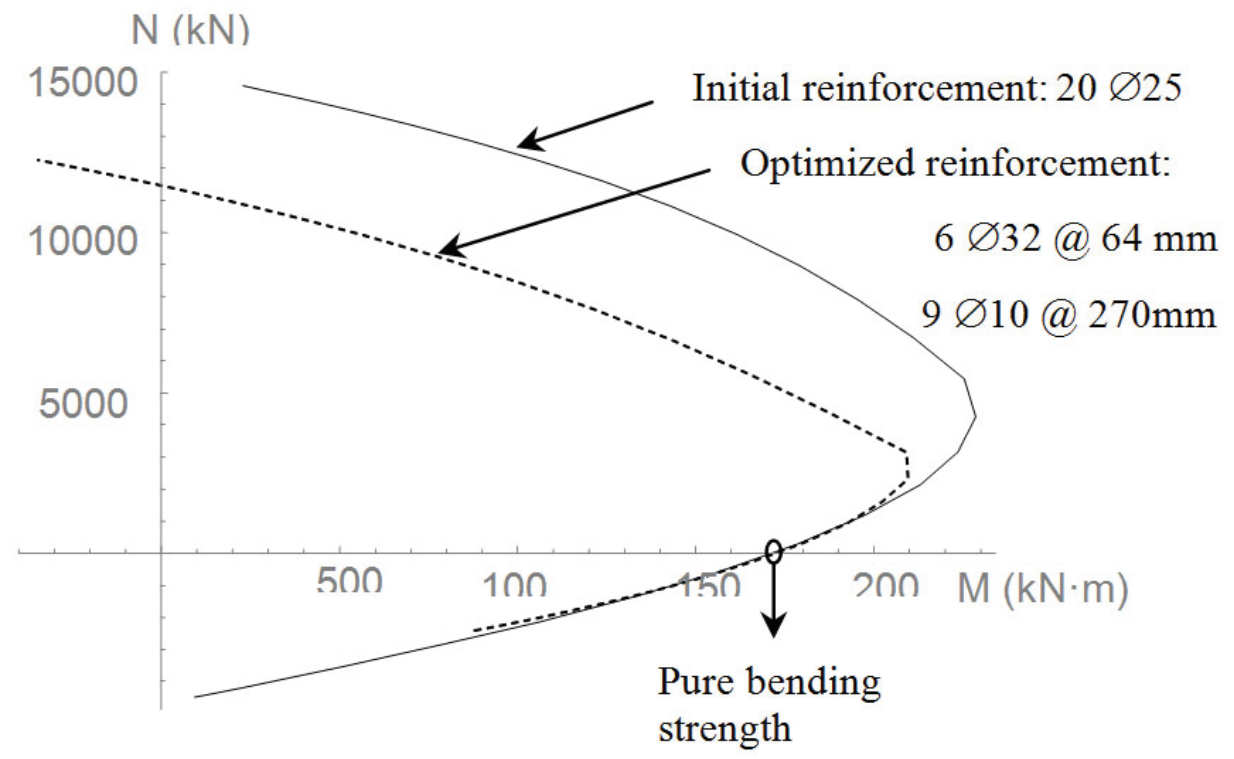

Figure 4 - Interaction N-M diagrams 


\section{Circular pier reinforced with embedded I shapes}

Sometime, instead of reinforcing the piles with steel rebar, a steel l-shape is introduced in the hole before pouring the concrete. This procedure is more common in the case of secant pile walls, in witch piles overlap to each other. In this case, applying a similar procedure than in the previous case, it is possible an optimization of the amount of steel. An important reduction of the embedded steel cross-section can be obtained without compromising the strength of the retaining wall pile. In the optimization procedure has been admitted that the centre of the web of the embedded steel shape coincides with the centre of the circle of the pier. A pier with a diameter of $600 \mathrm{~mm}$ has been studied. The conventional design used an IPE500 embedded shape. The design axial force is approximately zero. Steel was S235 having a characteristic strength of 235 $\mathrm{MPa}$. Concrete $\mathrm{C}-30$ had a nominal compressive strength of $30 \mathrm{MPa}$. The total area of steel initially embedded was $11173.6 \mathrm{~mm}^{2}$. Similarly to the case of piers reinforced with cages of steel, an optimization procedure had been implemented to reduce the area of embedded steel in piers subjected to pure bending conditions, i.e. when the design axial force is approximately zero. In this example, the thickness of the web of the optimized embedded shapes had been fixed equal to the corresponding value of the IPE-500 shape. In Figure 5, the optimized cross-section steel shapes, dimensions and areas are summarized.

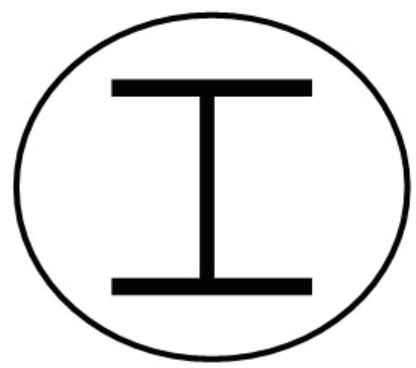

Initial shape:

$$
\begin{aligned}
& \mathrm{b}_{\mathrm{f} 1}=\mathrm{b}_{\mathrm{f} 2}=200 \mathrm{~mm} \\
& \mathrm{t}_{\mathrm{f} 1}=\mathrm{t}_{\mathrm{f} 2}=16 \mathrm{~mm} \\
& \mathrm{~h}_{\mathrm{w}}=468 \mathrm{~mm} \\
& \mathrm{t}_{\mathrm{w}}=10.2 \mathrm{~mm} \\
& \mathrm{~A}_{\mathrm{s}}=11173.6 \mathrm{~mm}^{2}
\end{aligned}
$$

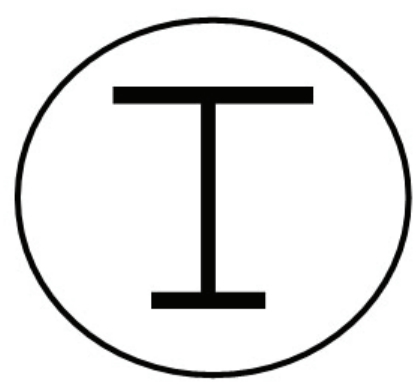

Single symmetrical I-Shape

$$
\begin{aligned}
& \mathrm{b}_{\mathrm{f} 1}=282 \mathrm{~mm} ; \mathrm{b}_{\mathrm{f} 2}=102 \mathrm{~mm} \\
& \mathrm{t}_{11}=\mathrm{t}_{\mathrm{f} 2}=14.2 \mathrm{~mm} \\
& \mathrm{~h}_{\mathrm{w}}=450 \mathrm{~mm} \\
& \mathrm{t}_{\mathrm{w}}=10.2 \mathrm{~mm} \\
& \mathrm{~A}_{\mathrm{s}}=10042.8 \mathrm{~mm}^{2}
\end{aligned}
$$

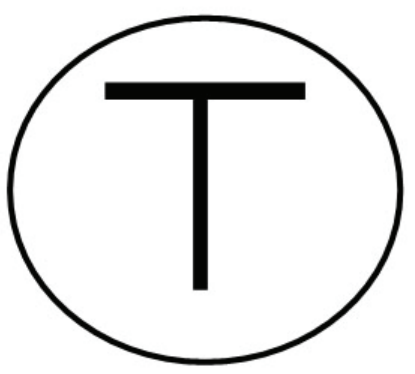

T-Shape

$$
\begin{aligned}
& \mathrm{b}_{\mathrm{f}}=272 \mathrm{~mm} \\
& \mathrm{t}_{\mathrm{f}}=18.2 \mathrm{~mm} \\
& \mathrm{~h}_{\mathrm{W}}=410 \mathrm{~mm} \\
& \mathrm{t}_{\mathrm{W}}=10.2 \mathrm{~mm} \\
& \mathrm{~A}_{\mathrm{s}}=9318.04 \mathrm{~mm}^{2}
\end{aligned}
$$

Figure 5: Initial (IPE 500 I-Shape) and optimized embedded steel shapes in circular piers of retaining walls. In this figure: $b_{f}$ is the width of the flange, $t_{f}$ is the thickness of the flange, $h_{w}$ is the height of the web, $t_{f}$ is the thickness of the web and $A_{s}$ is the area of the embedded steel cross-section

The interaction diagrams of the traditional and optimized piers with embedded steel are represented in Figure 6. This figure shows that the three solutions have the same pure bending strength while the optimized proposed solutions involve an important reduction of the amount of steel. In Figure 6 the steel contribution ratio $\delta$ (defined in Eurocode 4 [8]) has also been indicated.

\section{STEEL STRUCTURES}

The RSD technique can also be applied to the proportioning of steel cross-sections [06, 07]. For the design of a steel cross-section subjected to combined loads $\mathrm{N}$ and $\mathrm{M}$ also an infinite number of solutions exist. These solutions can be graphically represented to make easier the choosing of the most appropriate, similarly to the RSD representation for $\mathrm{RC}$ sections (Figure 1). In the optimization procedure of steel members, both strength and buckling requirements established in EC3 [09] were considered. The optimized procedure was applied to both compact and slender cross section steel.

\section{CONCLUSION}

In order to reduce the $\mathrm{CO} 2$ emission engineers and architects must optimize the use of materials, particularly steel, making an optimal use of 
this material. Especial attention has to be paid to the embodied energy associated with each one of the materials, i.e. steel and concrete. It is possible to guarantee the strength of the structural element reducing the amount of steel locating it properly at the cross-section and introducing a higher control level at jobsite.

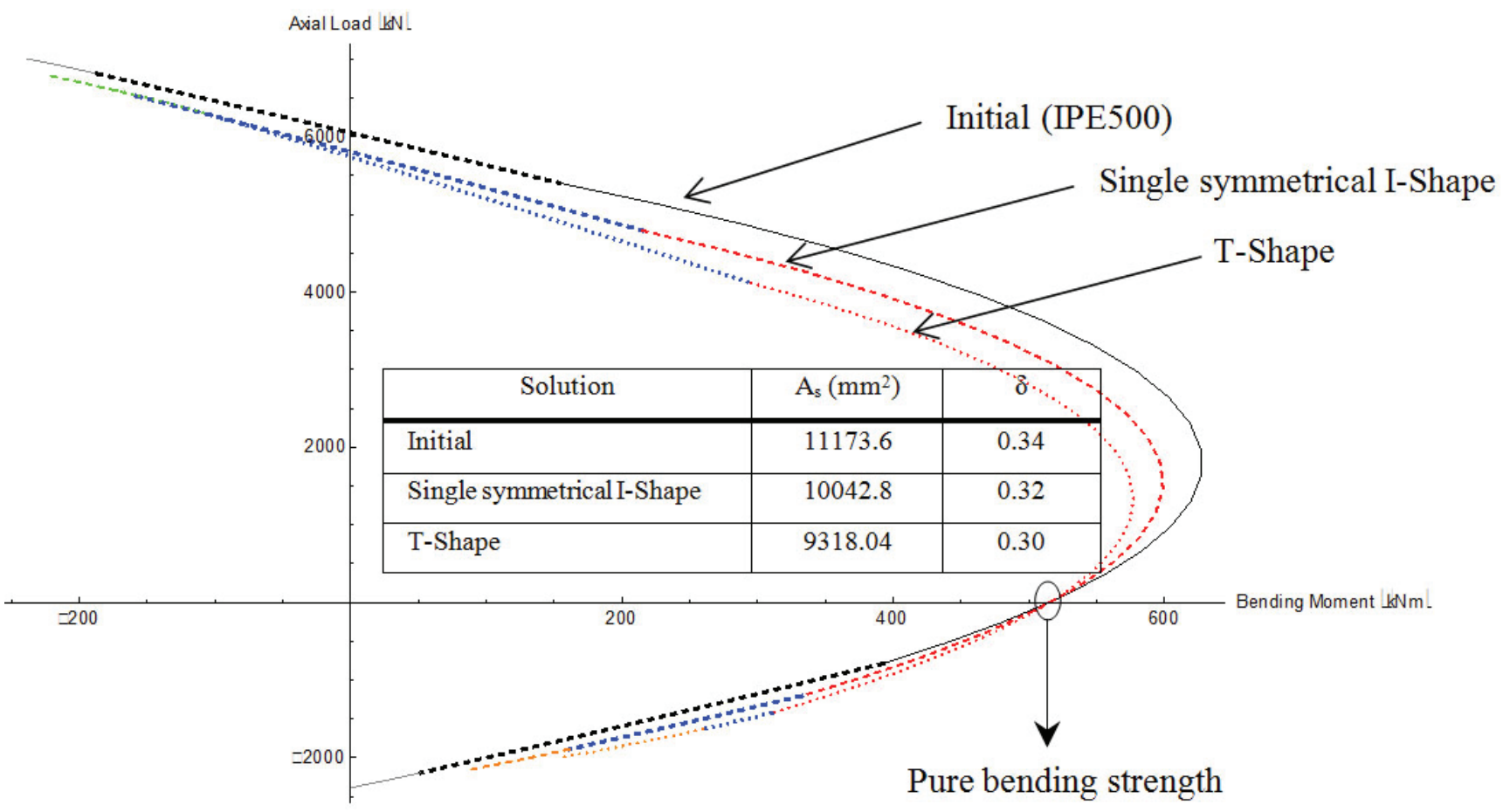

Figure 6: Interaction N-M diagrams

\section{REFERENCES}

1) E. Hernández-Montes, L.M. Gil-Martín, M. Pasadas-Fernández, M. Aschheim, "Theorem of Optimal Reinforcement for Reinforced Concrete Cross Sections". Structural and Multidisciplinary Optimization", Vol. 36, 2008, p. 509-521.

2) Eurocode 3. European Committee for Standarization. prEN1993-1-1. Eurocode 3. Design of steel structures. Part 1.1: General rules and rules for buildings. Brussels; 2005.

3) Eurocode 4. European Committee for Standarization. prEN1993-1-1. Eurocode 4. Design of composite steel and concrete structures - Part 1-1: General rules and rules for buildings. Brussels; 2004.

4) J.F. Carbonell-Márquez, L: M. Gil-Martín, E. Hernández-Montes, "Strength design optimization of structural steel members according to Eurocode3 ". Journal of Constructional Steel Research, Vol. 80, 2013, p. 213- 223.

5) L.M. Gil-Martín, E. Hernández-Montes, M. Aschheim, "Optimal reinforcement of RC columns for biaxial bending". Materials and
Structures/Materiaux Et Constructions, Vol. 43(9), p.1245-1256.

6) L.M. Gil-Martín, E. Hernández-Montes, M. Aschheim, "Optimization of piers for retaining walls". Structural and Multidisciplinary Optimization. Vol. 41 (6), June 2010, p. 979-987.

7) L.M. Gil-Martín, E. Hernández-Montes, M. Shin, M. Aschheim, "Developments in excavation bracing systems". Tunnelling and Underground Space Technology, Vol. 31, 2012, p. 107-116.

8) L.M. Gil-Martín, M. Aschheim, E. HernándezMontes, "Proportioning of Steel Beam-Column Members Based on RSD Optimization Methodology“. Engineering Structures. Vol. 30, 2008, p. 3003-3013.

9) L.M. Gil-Martín, M. Aschheim, E. HernándezMontes, "Proportioning of steel beam-column members based on RSD optimization methodology". Engineering Structures, Vol. 30(11), 2008, p. 3003-3013.

Paper sent to revision: 07.02.2014.

Paper ready for publicatuion: 15.03.2014. 